\title{
A PLAYFUL PROGRAM TO RISE CLIMATE CHANGE AWARENESS IN THE PRIMARY SCHOOL
}

\author{
A. RÁZSI ${ }^{1}$, Boglárka TÓTH ${ }^{1}$
}

\begin{abstract}
A Playful Program to Rise Climate Change Awareness in the Primary School. The aim of the program is to draw the primary school children's attention to the phenomenon of climate change, including its causes, consequences, and to key options of climate conscious life-style. Meanwhile, changes in knowledge of the children who participate in the program are measured. We have developed a program to raise awareness, which can be realised in an afternoon session at any public school.. In the first step we describe the substance of climate change by a film and a short lecture, then we further deepen the children's knowledge by playful exercises in a steeplechase consisting of six different 'stations'. The paper describes the tasks at the 'stations' and the results of knowledge tests before and after the program.
\end{abstract}

Keywords: climate change, awareness raising, steeplechase, knowledge tests

\section{INTRODUCTION}

One of the biggest challenges, facing humanity, is climate change.

The increase in carbon dioxide levels in the primary consequence of the global temperature rising which has been signs as already seen. (IPCC, 2013) Seemingly a slight few degrees rising has very serious consequences which signs are already perceptible, unfortunately, however, the responses of humanity apparently are not in proportion to increasing signs, which are clearly a result of climate change The reason that a significant part of humanity even climate-sceptic - among other things - it is also possible that they often receive contradicting information about climate change.

Environmental education should be started teaching to small children which in most cases has been realized, however, the climate-conscious education usually has not enough priority. Of course, it is important to teach the younger generation's the love of nature, purely for the environment or personal hygiene, but the climate awareness should be given priority treatment at the environmental education. It is important that the coming generation is being aware of about the climate change causes, consequences, and what could be taken to mitigate climate change.

We developed a program which is primarily can be used for 9-10 years old children and it could be realized any school in an afternoon session time.

${ }^{1}$ razsi.andras@uni-eszterhazy.hu; bogi130@freemail.hu 
Participants can learn in a playful way about climate change causes, consequences and how to live climate-consciously life. The program was tested at three Hungarian schools in May 2016.The children had to fill out a test before and after the program, so it turned out how their knowledge changed after they played out the tasks.

\section{THE CLUB ACTIVITIES}

At the beginning of the session, a part of short film was presented, which was made for small children about climate change. It was followed by a short, fiveminute presentation to emphasise some important parts and to deepen what was said in the film.

Then came the games at the stations of the steeplechase, as follows:

\subsection{Crossword}

A classic, simple crossword had to be solved by the children, which solution was: THIRTY-THREE. The solution is the number of centigrades in average by which our Earth would be colder without the greenhouse effect. It is important to realize the greenhouse effect is a natural process and there would be no life on Earth without that.

\subsection{Quiz}

There a 10-question multiple-choice test had to fill out, which were connected with the film and the short presentation afterwards. After the children filled out the test, the correct answers were abnounced and discussed at the place. The questions mostly focused on the causes of climate change.

\subsection{Selected rubbish bins}

At this station we emphasized the importance of selective waste collection. To the session we took a large dose of selectively collected waste (paper, plastic, glass, aluminium cans), which was mixed there. The task was the waste were being sorted out as quickly as possible into the selected rubbish bins.

\subsection{Digital puzzle}

On the Internet there is a site where after registration you can edit your own puzzle. (http://www.jigsawplanet.com/) With the help of an available projector, the puzzle games, edited by ourselves, were projected to the children. These images illustrated the consequences of climate change.

Fig. 1. Images of the puzzle game

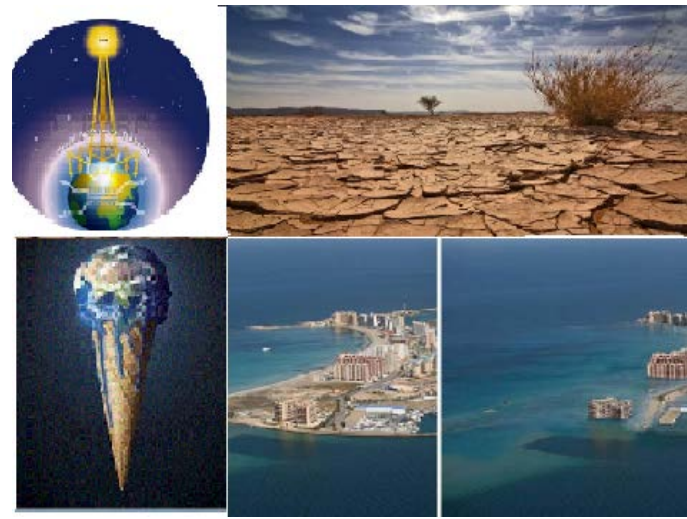




\subsection{Activity game}

During the game, participants were selected to explain us a definition by gestures and movements, without any word spoken. One child could choose and pantomime one definition. The definitions presented the consequences of climate change and the ways how an individual can reduce the changes.

The definitions were:

- Desertification

- Melting ice caps

- Composting

-Selective waste collection

- Saving energy

- Collecting paper

- Dripping taps

- Strong storms

- Tree planting

- Rising temperatures

Fig. 2. Afternoon club session in a public school

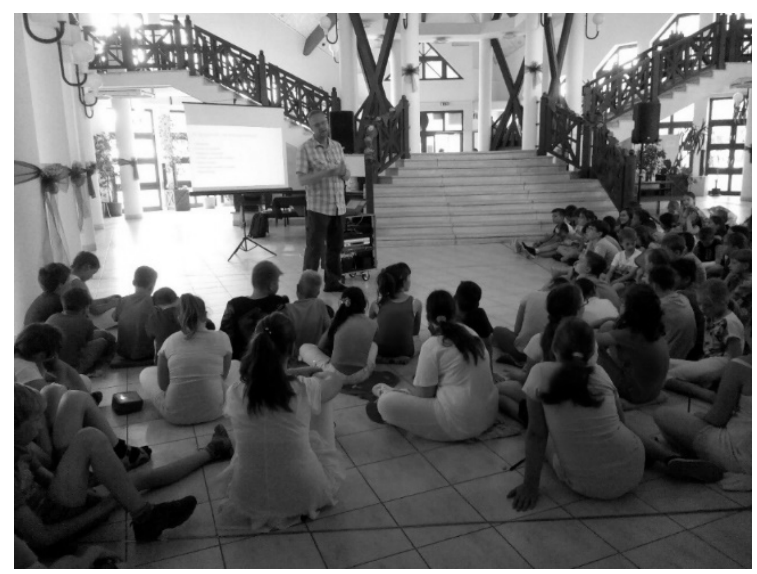

\section{THE TEST}

The test, which had to be filled by the children before and after the session, wanted to explore how they are aware of the real causes, consequences about climate change and how to live everyday life to be really climate-conscious.

We asked the participants what they thought about climate change, what were the properties of carbon dioxide, and what would be these the consequences, if the amount of it continues to rise and what we can do to use less carbon dioxide, which released into the atmosphere. When the questions were edited by ourselves we paid attention to be understood for 9-10 years' children. such everyday activities were featured that they have already made daily (transport, lift usage, nutrition, waste collection).

\section{RESULTS}

\subsection{The most important questions}

The session was carried out in three schools, accordingly altogether 238 children participated in it. A few days before and after the session the test had been filled out by all participants.

By evaluation of tests we measured how much the children's knowledge had changed a result of the session. This is shown by the answers of the test. Before the session $57 \%$ of the participant's answers were correct, while after the 
session there were $74 \%$. Overall, the participants' knowledge was improved by $17 \%$ as a result of an two-hour playful session.

At the last question children had to give an opinion on how important for them to protect the climate. They could give an answer from 1 to 5.5 meant that very important - and 1 meant that - not at all important -. Before the session the average of the answers was 3,5 after the session it was 4,4. It means that managed to raise interest about the theme.

When this sentence was claimed in the test: " Every people - including me - is responsible for climate change" before the session $59 \%$ had agreed with it, after the session it was $84 \%$. So, more than a quarter of children's attitude have changed. This is especially a good result because nearly $60 \%$ of them had concerned about it already before the session.

\subsection{Questions about the greenhouse effect}

One of the questions referred to the greenhouse effect, where had to be chosen the right solution of three possible answers. Before the test the half of participants had given good answer, while after the session $80 \%$ gave correct answer.

The other question referred to how many number of degrees would be cooler the Earth temperature without the greenhouse effect. Before the session only $10 \%$ of the children had got correct answer, while after $75 \%$ knew the right solution. This question was important because children were faced with the fact, how much important the greenhouse effect. It is a positive effect, because without it there would not be any life on Earth and it would be a frozen planet. (Fig. 3.)

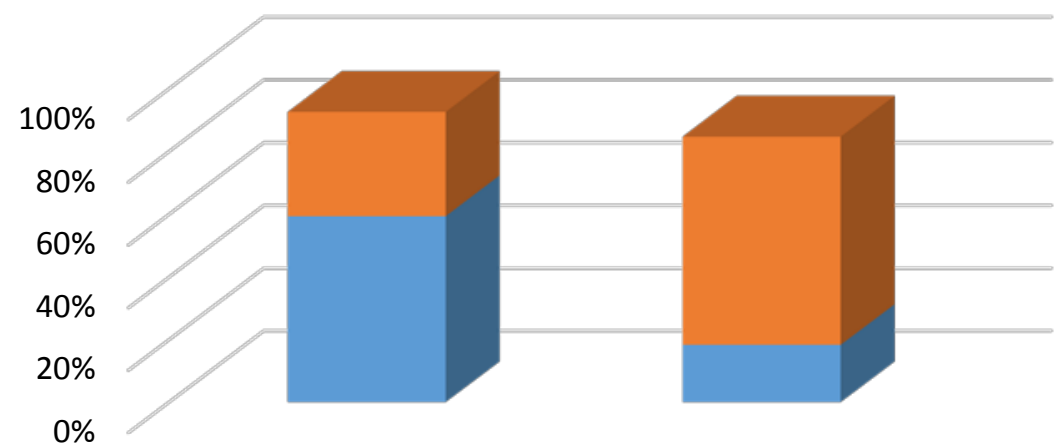

1. What is the greenhouse

2. How much would be

effect?

colder

without greenhouse effect?

Before Changes

Fig. 3. Given answers on the questions of greenhouse effect, before the session and the changes 


\subsection{The causes and consequences of climate change}

In this Section statements were defined in the test and the children had to decide which statement is true or false. Fig. 4. shows the results.

It shows, that most of the question there are not any significant change, however, it is remarkable when we stated: "Without the greenhouse effect there would not be any life on Earth" we can find significant change between the observed input and output measurements.

The other significant change was in the question about individual responsibility which mentioned in Section 4.1. The answers refer to that the significant proportion of the children understood the necessity of the natural greenhouse effect, and that, they can make efforts to moderate climate change.

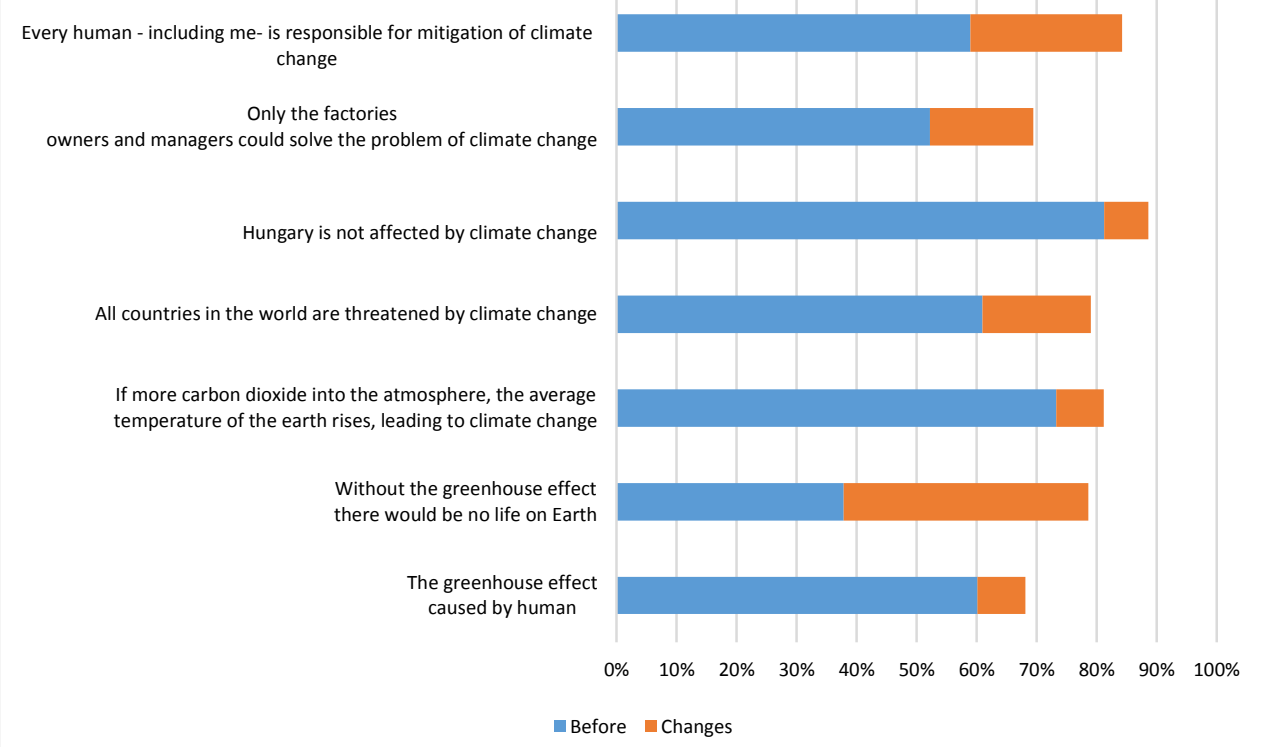

Fig. 4. Questions and answers about reasons and consequences of climate change

At the task of global consequences had to be chosen from the listed natural and social phenomena, which are expected to come. The input test answers showed rather mixed results, but the output test it was only one phenomenon that had not reached $50 \%$, it is the ozone layer. In the session problem of the ozone was not mentioned, it is an another anthropogenic problem.

Many others think incorrectly that problem of the ozone is related to climate change. Significant improvement are seen in the recognition of great migrations, as a consequence of climate change. Other significant improvement is understanding the higher number of undesired natural phenomena (Fig. 5). 


\subsection{The individual's responsibility}

The main objective of the program was that to teach children how to live climate-conscious life. In the test there were statements which were not correct in terms of climate protection - this fact was told to the children. The children's task described what is appropriate behaviour and everyday actions instead of the incorrect statements. Fig. 5. shows the results.

We drew attention to the fact if people omit the meat from the diet only once a week, we will save a lot of carbon dioxide. It seems, many children have understood these facts.

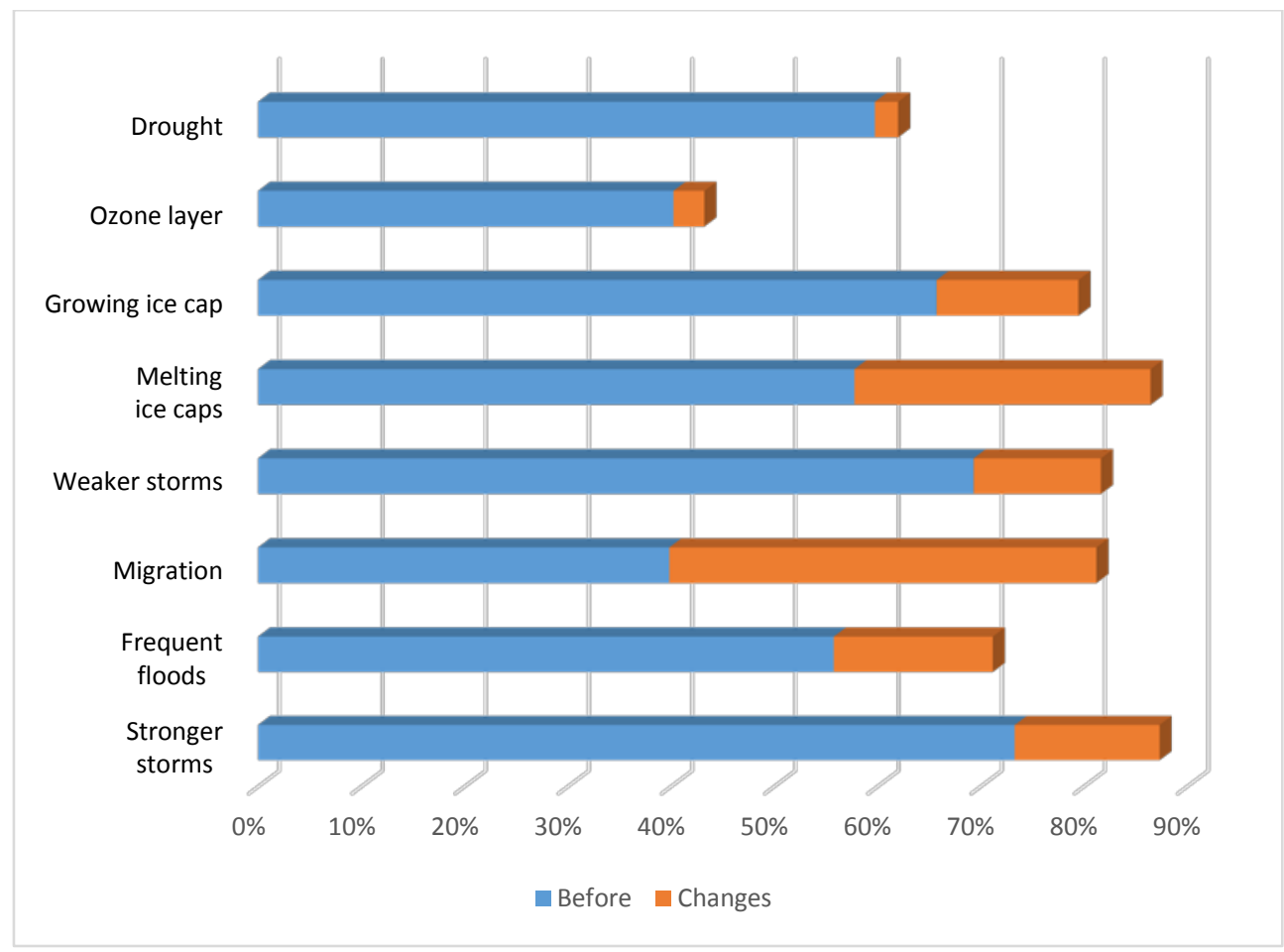

Fig. 5. The results on recognition of global consequences of climate change

There were emphasized at transportation, if it is possible, avoid the use of machines, for example we can use own strength to go to upstairs instead of using elevator or not only travelling by car, if we can cycling or walking too.

In these questions at the input answers also showed good results possibly because in other health- conscious session they had heard about it. After the session it seemed to more children aware of these information.

One of the statements was "I buy everything, what I would like to. „Less than the half of participants answered that overconsumption is inappropriate behaviour, while after the session 90\% have known the correct answer. 


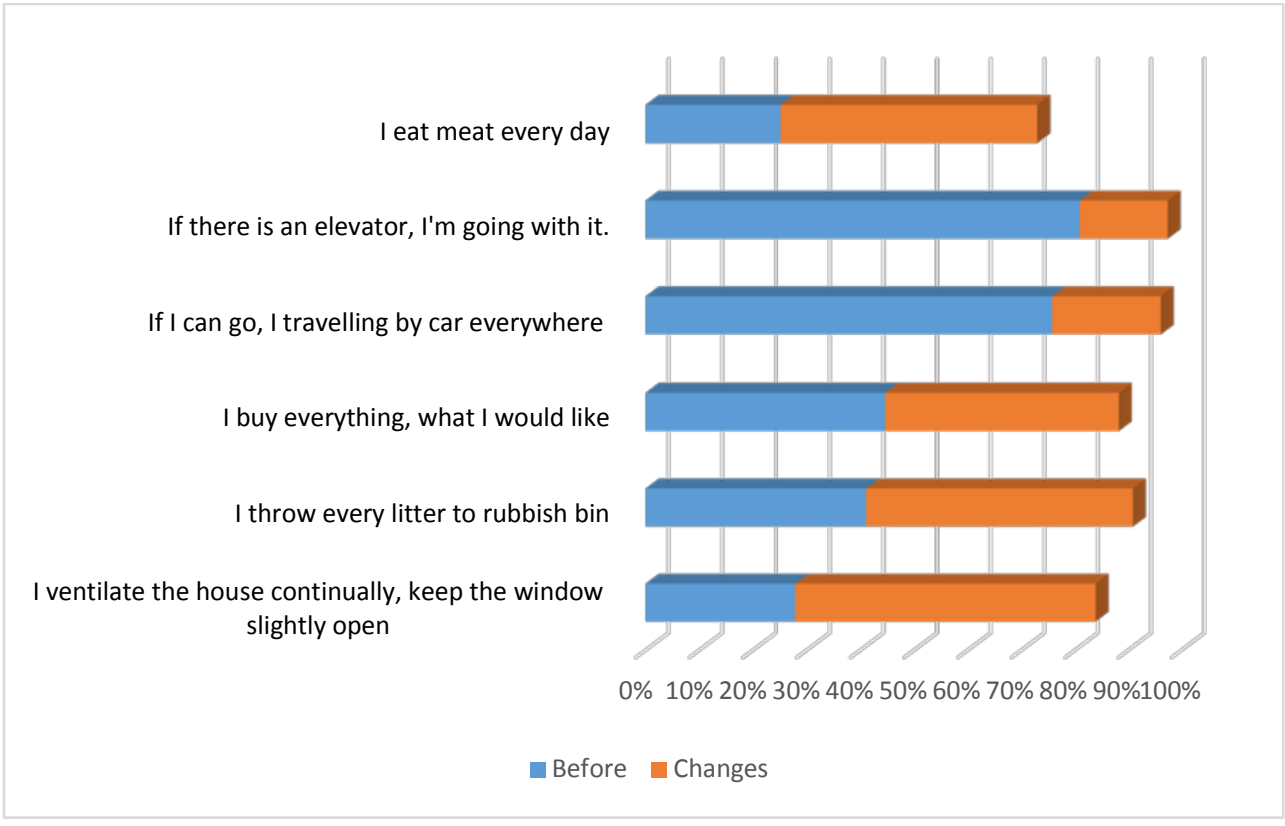

Fig. 6. The correct everyday actions in terms of climate protection

The proper waste collection is also concerned by many children in this session. They thought the littering is an inappropriate behaviour, but in results of the output answers $90 \%$ of children considered the importance of selectivity. After the session most of children have been able to give correct answer about the ventilation habits which are properly in terms of climate protection.

\section{CONCLUSION}

We have developed an afternoon session for 9-10 year-old primary school children, the aim of the program was that to explain the causes and consequences of climate change and how we can live climate-consciously in everyday life.

In order to find out what about the observed children knowledge, how much their knowledge is changing the results of the session, we have developed a knowledge evaluation test, which was filled out by the participants before and after the session.

The test showed that the biggest change what the individuals can do is to be climate-conscious in their everyday actions. The more significant changes can be shown at the causes and consequences of climate change.

It was an only a two-hour session, so the result is remarkable. On the other hand, further sessions, programs and training materials should be developed, to achieve that these things about climate change become completely natural for the young generation. For the today's society it still needs to be explained. 


\section{REFERENCES}

1. IPCC (2013): Climate Change 2013: The Physical Science Basis. Contribution of Working Group I to the Fifth Assessment Report of the Intergovernmental Panel on Climate Change [Stocker, T.F., et al. (eds.)]. Cambridge University Press, Cambridge, UK \& New York, USA, 1535 pp.

2. https://ipcc.ch accessed on January, 12, 2017

3. https://www.youtube.com/watch?v=rEBDzOeWqX0\&index=14\&list=PL2 accessed on January, 12, 2017

4. http://www.jigsawplanet.com/ accessed on January, 12, 2017 